\title{
A Mixed-methods Approach to Understanding the Perspectives, Experiences and Attitudes of Cognitive Behavioral Therapy for African American Patients with Type-2 Diabetes: A Randomized Parallel Design Pilot Study
}

\section{Ronald M. Cornely}

Rollins School of Public Health: Emory University School of Public Health https://orcid.org/0000-00031678-7509

\section{Vinita Subramanya}

Rollins School of Public Health: Emory University School of Public Health

Ashley Owen

Emory University School of Medicine

\section{Robin E. McGee}

Rollins School of Public Health: Emory University School of Public Health Ambar Kulshreshtha ( $\nabla$ akulshr@emory.edu )

Rollins School of Public Health: Emory University School of Public Health https://orcid.org/0000-00034610-1352

\section{Research}

Keywords: African American, Type 2 Diabetes, Cognitive Behavioral Therapy

Posted Date: October 29th, 2021

DOI: https://doi.org/10.21203/rs.3.rs-1005352/v1

License: (c) (i) This work is licensed under a Creative Commons Attribution 4.0 International License.

Read Full License 
1 A Mixed-methods Approach to Understanding the Perspectives, Experiences and Attitudes

2 of Cognitive Behavioral Therapy for African American Patients with Type-2 Diabetes: A Randomized Parallel Design Pilot Study

4

5 Ronald M. Cornely MPH${ }^{1}$, Vinita Subramanya MBBS, $\mathrm{MPH}^{2}$, Ashley Owen, $\mathrm{PhD}^{3}$, Robin E.

6 McGee $\mathrm{PhD}^{1}, \mathrm{MPH}$, Ambar Kulshreshtha, $\mathrm{MD}, \mathrm{PhD}^{1,2}$

7

8
1. Behavioral, Social, \& Health Education Sciences Department, Rollins School of Public Health, Emory University, Atlanta, GA

2. Dept. of Epidemiology, Rollins School of Public Health, Emory University, Atlanta, GA

3. Dept. of Family and Preventive Medicine, Emory University School of Medicine, Atlanta, GA

\section{Word count:}

Abstract: 282 (of 350 words)

Main text: 5522

References: 40

Tables: 2

Figures: 5

\section{Corresponding Author:}

Ambar Kulshreshtha, MD, PhD

Department of Family and Preventive Medicine, Emory University School of Medicine Department of Epidemiology, Emory Rollins School of Public Health 4500 North Shallowford Rd.| Suite 134 | Atlanta, GA 30338

Phone: 404-778-6910 | Fax: 404-778-6901 | akulshr@emory.edu 
57 Results: Fourteen participants completed the study, their mean HbA1c improved from $8.5 \%$ to

\section{Abstract:}

Background: African American (AA) adults are $60 \%$ more likely to be diagnosed with diabetes mellitus (DM) and experience more complications than non-Hispanic White adults. Cognitive behavioral therapy (CBT) is a technique that combines traditional care with cognitive and psychosocial techniques. We aimed to assess the effects of CBT integrated with motivational interviewing (MI) on glycemic control in AA participants and understand their perspectives, attitudes, and experiences toward CBT.

Methods: Using a randomized, parallel design pilot study (web-based group vs in-person group), 20 participants aged $\geq 18$ years, identifying as AA, and having a glycosylated hemoglobin $(\mathrm{HbA} 1 \mathrm{c})>8 \%$, were recruited. CBT was administered in six sessions over three months. Participants completed baseline and follow-up assessments on measures for diabetes control (HbA1c), self-efficacy, generalized anxiety, depression, perceived stress, health-related quality of life and cognitive ability. Post-CBT focus groups were conducted to determine patient perspectives regarding the intervention.

7.7\%. The Diabetes Distress Scale demonstrated decreased distress overall $(\mathrm{t}(26)=2.6 ; \mathrm{p}-$ value=0.02). The Generalized Anxiety Disorder Scale demonstrated decreased generalized anxiety for all participants $(\mathrm{t}(26)=2.2 ; \mathrm{p}=0.04)$. Themes identified in focus groups included: $(1)$ intervention group social support through information sharing; (2) mental health and personal identities in diabetes understanding and management; (3) receptivity to CBT/MI Intervention positively impacts self-efficacy through improved health literacy. 
64 Conclusion: Group-based CBT intervention for type $2 \mathrm{DM}$ care was positively received by AA

65 participants and helped improve diabetes control, as demonstrated by the change in HbA1c.

66 There were additional benefits of social support through group interactions and a stronger sense

67 of self-efficacy due to health education. A comprehensive treatment plan like CBT, may be

68 useful in promoting healthy diabetes self-management.

69

70 Trial registration: This trial is registered at ClinicalTrials.gov with the identifier NCT03562767.

71 Registered 19 June 2018,

72 https://clinicaltrials.gov/ct2/show/NCT03562767?term $=$ NCT03562767\&draw $=2 \&$ rank $=1$

73

74

75 Key Words:

76 1) African American 2) Type 2 Diabetes 3) Cognitive Behavioral Therapy

77

78

79

80

81

82

83

84

85

86 


\section{Key Messages Regarding Feasibility:}

88 1) What uncertainties existed regarding the feasibility?

89 At the start of the trial, investigators were concerned about the feasibility of using a technology-

90 based intervention in an older age group- in terms of both, access and uptake. Another concern

91 was the level of comfort among participants during discussions pertaining to their medical

92 condition and barriers in achieving optimal health.

93 2) What are the key feasibility findings?

94 This study demonstrated that technology was not a barrier for participation and retention of study

95 participants. It indicated that group and web-based interventions were feasible and acceptable.

96 3) What are the implications of the feasibility findings for the design of the main study?

97 Future studies with a larger sample size, exploring the acceptability and effects of cognitive

98 behavior therapy on diabetes mellitus control in African American people, are feasible.

99

100

101

102

103 


\section{Background:}

106 In 2018, about $10 \%$ of the total US population was estimated to have diabetes mellitus (DM) (1).

107 According to the Centers for Disease Control and Prevention, diabetes has been documented to

108 have a disproportionate impact on the African American (AA) population of the United States

109 (2). AA adults are 1.7 times more likely to develop diabetes as non-Hispanic White adults and

110 twice as likely to die from diabetes (2). These disparate diabetes outcomes have been linked to

111 traditional risk factors such as obesity and lower socioeconomic status (SES), as well as risk

112 factors attributed to the environment and lifestyle choices of AA adults (3).

113 AA adults are more likely to receive a physician diagnosis of DM, have worse glycemic control

114 and have more DM-related complications compared to non-Hispanic White adults (4-7). Risk

115 factors for DM are also more prevalent in the AA population, such as a 1.3 times greater

116 likelihood of obesity when compared to Non-Hispanic White adults (8). Other related risk factors

117 seen in the AA population at higher rates include, hypertension, high cholesterol levels and

118 smoking. Additionally, depression, anxiety and diabetes-related specific concerns are common

119 comorbidities in people with DM (9-11). The relationship between DM and these co-morbidities

120 is complex, since they are thought to influence each other and are affected by biological and

121 psychosocial pathways (12). The interaction between DM and related comorbidities adds a

122 complex behavioral aspect of diabetes management, since it requires tasks with self-care

123 components such as activity, diet, adherence and compliance with treatment regimens, self-

124 monitoring of glucose levels, and making and keeping healthcare appointments. 
126 Further aggravating the impact of type 2 diabetes on AA adults are racial discrimination and low

127 SES. These two factors are respectively associated with poorer health outcomes and a greater

128 prevalence of diabetes $(13,14)$. Even after accounting for factors related to socioeconomic

129 position, access to healthcare and severity of disease, these racial/ethnic differences in glycemic

130 control persist $(5,6)$. The greater risk and diabetes burden in AA patients suggests a need for

131 tailoring interventions in this high-risk group.

132

133 Psychological interventions such as cognitive behavioral therapy (CBT) have been shown as

134 effective for overcoming behavioral barriers related to self-care and improve glycemic control

135 among people with diabetes. CBT combines traditional care with cognitive and psychosocial

136 techniques to address thoughts, beliefs, and behaviors detrimental to self-care and replace them

137 with more helpful thoughts and behaviors. CBT has previously been used to account for

138 depression in diabetes care and assess biological markers of diabetes along with behavioral

139 outcomes of diabetes management $(15,16)$. Systemic reviews of CBT-based interventions on

140 glycemic control have found that CBT may be beneficial in improving glycemic control and

141 other aspects of psychological health, such as depression $(17,18)$. Furthermore, since non-

142 compliance is one of the most commonly cited reasons for CBT-based therapy failure (19), we

143 believed that modifying our CBT approach by integrating Motivational Interviewing (MI) into

144 the delivery of the intervention would support participants' engagement. Engagement is a

145 foundational pillar of MI, in the process of learning, and applying CBT content. Therefore, we

146 integrated MI into this intervention as a delivery process to encourage patients' acceptance

147 and motivation to practice CBT skills that promote healthy lifestyle choices. 
148 There are no studies that have examined the effects of an integrated CBT/MI intervention in a

149 group-based format among AA patients and examined its effects with uncontrolled diabetes. Our

150 pilot study aimed to assess the efficacy of this CBT/MI intervention related to glycemic control

151 in AA participants and understand their experience and assess their perspectives and attitudes

152 toward this CBT/MI intervention.

153 Methods:

154 Study design and setting: The LIGHT (Lifestyle Intervention Guidance for a Healthier

155 Tomorrow) study was a randomized, parallel design pilot clinical trial. It was conducted at the

156 Dunwoody Family Medicine Clinic, Emory University, Atlanta, GA in 2019. The participants

157 were administered a behavioral intervention (CBT) program, from March 2019- May 2019, with

158 the administration of initial study scales shortly before beginning the study in March of 2019 and

159 the collection of follow-up data in May of 2019. It used a mixed methods approach with

160 quantitative and qualitative study methods to assess glycemic control, perspectives, experiences

161 and attitudes of AA patients with diabetes mellitus. The trial was registered at ClinicalTrials.gov

162 (identifier: NCT03562767).

163

164 Study population: (Figure 1) Participants were recruited from primary care clinics by various

165 study staff at Emory through phone calls or letters. Eligibility criteria for this study included, age

$166 \geq 18$ years, fluency in English, identifying as AA and, having a glycosylated hemoglobin

167 (HbA1c) level of over 8\% (an indicator of uncontrolled diabetes mellitus). Participants were

168 excluded if they did not have internet access, used insulin pumps, were pregnant, actively

169 misused substances (including alcohol) and had visual or physical impairments that did not allow 
170 them to complete study activities. Participants were followed-up for a three-month period. From

171 the initial 20 participants who were recruited, 14 participants completed the study with 7 in each

172 intervention group. The six study participants who did not complete the study either failed to

173 attend a sufficient number of intervention sessions or were missed follow-up visits for post-study

174 data collection. All participants provided informed consent and research activities were approved

175 by the Emory Institutional Review Board.

176

177 Cognitive behavior therapy intervention: Participants were randomized using computer

178 generated random numbers to one of two CBT/MI formats - a web-based and an in-person

179 format. Both formats had six 1-hour sessions, every 2 weeks for three months, focusing on food

180 planning education (15 minutes) and culturally specific CBT presentations and interactive

181 activities (45 minutes). The in-person format allowed for group interaction which was limited in

182 the web format. The inclusion of both formats in a study assessing CBT is a novel technique.

183 This intervention was led by a licensed psychologist who had extensive experience providing

184 CBT and MI treatment to African American patients. This individual is a member of the

185 Motivational Interviewing Network of Trainers (MINT). As a MINT member, this psychologist

186 is experienced in training clinicians to support participants' engagement and motivation to make

187 health behavior changes, including implementing CBT skills. The licensed psychologist trained

188 the study facilitator using the Motivational Interviewing Treatment Integrity Coding Manual

189 (MITI) 4.2.1 (20). Using the coding manual's evaluation standards to

190 determine competence, the study facilitator was determined to have met a "good" (highest

191 category) threshold of clinician competence and proficiency in applying MI. 
193 Evidence suggests that, in general, adapted interventions outperform non-adapted interventions,

194 and are preferred by African American populations (21, 22). Thus, we determined that

195 developing behavioral health interventions for MCI-related cognitive and functional decline in

196 ways that are culturally relevant to African American patients was important. To access expertise

197 in cultural tailoring, we worked with an African American clinical psychologist and researcher

198 who had expertise in both CBT and the cultural-adaptation of evidence-based interventions for

199 African American patients. The intervention team received implicit bias training, lectures, and

200 ongoing consultation from our cultural tailoring content expert in order to learn about

201 sociocultural considerations relevant to African American people and increase awareness of

202 microaggressions that are commonly overlooked or dismissed (23). Bi-weekly, the cultural

203 tailoring content expert met virtually with the intervention team to provide feedback on drafts of

204 each module. The goal of this feedback was to understand cultural considerations and strategies

205 for integrating African American cultural values into the intervention.

206

207 Quantitative assessments: At baseline and during follow-up, participants were administered

208 paper-based survey questionnaires that collected information on demographics. They also

209 answered surveys on self-efficacy, generalized anxiety severity, depression severity, perceived

210 stress, health-related quality of life (HRQoL), and cognitive ability. Sociodemographic

211 information of interest included age, gender, education level, and marital status, all of which

212 were self-reported. Participant body mass index (BMI) was used to determine obesity status

213 (normal weight, overweight, obese). Additionally, glycosylated hemoglobin (HbA1c)

214 information was obtained for all participants from Electronic Medical Records and Point of Care

215 Testing, at baseline and during follow-up. 
216 The measure of self-efficacy was collected using the Self-Management Resource Center's Self

217 Efficacy for Diabetes scale (24). This 8-item scale assesses self-efficacy in diabetes self-

218 management. A score closer to 10 is indicative of greater self-efficacy. The Diabetes Distress

219 Scale is a 17-item, 6-point Likert, scale that evaluates the severity of emotional distress

220 experienced by a person with diabetes (25). It provides an overall score and one for each of the

221 following dimensions: emotional burden, regimen distress, interpersonal distress and physician

222 distress. The patient's responses associated with each of the four dimensions were summed then

223 divided by the number of items in the given dimension. The mean of the responses to all 17

224 items was calculated to determine the overall distress experienced. A mean score of 3 (moderate

225 distress) or higher is serves as the indicator for clinical attention for study participants.

226 Generalized anxiety in the two weeks prior to the scale's administration was assessed using the

227 Generalized Anxiety Disorder (GAD) Scale- 7 (26). It assesses the degrees to which participants

228 feel anxious, nervous or restless. A higher score indicates greater severity of anxiety. The Patient

229 Health Questionnaire (PHQ)-9 scale assesses the severity of depression, a higher score is

230 indicative of greater severity of depression (27). The Perceived Stress Scale (PSS) was used to

231 assess the extent to which participants identify situations in their life as stressful, within the past

232 month (28). A higher score suggests greater perceived stress. Health-Related Quality of Life

233 (HQRoL) was assessed using the RAND-36 survey (29). It is a scale which assesses eight health

234 concepts: physical functioning, role limitations caused by physical health problems, role

235 limitations caused by emotional problems, social functioning, emotional well-being,

236 energy/fatigue, pain and general health perceptions (29). Each of these health concepts are

237 scored continuously (0-100), higher scores suggest a more positive perception of HRQoL. The

238 Montreal Cognitive Assessment (MoCA) scale screens for cognitive dysfunction and assesses 
239 different cognitive domains through performance of twelve different tasks (30). A sum of item

240 scores is used to determine cognitive ability, a score of $\geq 26$ is considered 'normal.'

241 Qualitative assessments: Following the CBT/MI intervention, focus group sessions were

242 conducted to evaluate the receptivity of the CBT/MI intervention among participants through

243 semi-structured focus group discussion (FGD). Based on the intervention format to which they

244 were randomized, participants were assigned to separate focus groups- one focus group for the

245 web-based intervention and one group for the in-person intervention. These sessions were 25

246 minutes in length and were conducted in-person in one of Emory University Healthcare System

247 Dunwoody clinic's conference rooms. The sessions were audio recorded by the interviewer and

248 there was a student collaborator present as a notetaker during each session.

249 The Diffusion of Innovations theoretical framework was used in designing the interview guide

250 found in Appendix A. This model is designed to communicate new knowledge to members of

251 target groups through four main elements: innovation, communication channels, social system

252 and time $(31,32)$. The innovation being assessed is the Cognitive Behavioral Therapy through

253 web-based and in-person intervention formats. Communications channels were the culturally

254 tailored materials presented to participants during the study. The social system is the target

255 population: Black or African American patients with type-2 diabetes. The time is the

256 incorporation of the study over a six-session intervention time frame. The Diffusion of

257 Innovations model helped incorporate these key elements into the interview guide to

258 theoretically frame the information garnered from study participants.

259 The focus group discussion questions aimed to capture participants' perspectives, attitudes, and 260 experiences with the CBT/MI intervention. The post-study focus group session evaluated study 
261 acceptability and cultural congruence of the CBT/MI intervention through semi-structured group

262 discussions. The focus groups aimed to assess compatibility, complexity, observability, and

263 relative advantage of a culturally tailored CBT/MI for AA patients. It also aimed to assess the

264 cultural sensitivity of the study.

265

266 Data analysis:

267 Quantitative analysis: Baseline characteristics of study participants were assessed using t-tests 268 and chi-square tests, as needed. Baseline and follow-up assessments of quantitative scales were 269 assessed for change in scores. This was done among the overall study population as well as by 270 intervention group. For continuous scales, paired t-test were used to assess change and for

271 categorical scales, chi-square tests were used. Statistical significance was set at an alpha level of 272 .05. Quantitative analyses were performed on SAS 9.4 M software.

274 Qualitative analysis: Audio-recordings were transcribed and imported into the MAXQDA 275 analysis software. For each transcript, initial memos were developed to obtain familiarity of 276 information in each interview. This was followed by development of a codebook containing

277 names and definitions of codes and sub-codes that were developed. The codebook can be

278 accessed in Appendix B. The transcripts were then coded by a student collaborator at the Rollins

279 School of Public Health, who's coding techniques were discussed with the team and approved.

280 Once coded, the codes and coded segments were reviewed to develop overarching themes

281 describing related codes. Overarching themes were determined by assessing coding co-

282 occurrence and proximity of codes through the MAXQDA code map function. A preliminary

283 code map (Figure 2) was used to assess co-occurrence and coding similarities of all codes. The 
284 subsequent code maps (Figures 3-5) were derived from the preliminary code map to determine

285 the thematic threads of the study. Themes were further developed by exploring differences and

286 similarities in perspectives expressed in each intervention group. A second cycle of coding was

287 completed by reviewing matrices of related codes and by comparing and contrasting themes

288 between the two intervention groups. Quotes were identified that illustrated identified themes.

289 Results:

290

291 Participant characteristics: (Table 1)

292 Participants had a mean age of $56 \pm 9.4$ years, $79 \%$ identified as women $(n=11)$. About half the 293 participants had a college degree or higher and half reported being currently unmarried. The 294 mean duration since a diagnosis of diabetes was $13 \pm 5.3$ years. BMI measurements categorized $29564 \%$ of participants as obese. Demographic information can be found on table 1.

296 Quantitative results: (Table 2)

297 The Self Efficacy for Diabetes scale results demonstrated a statistically insignificant decrease in 298 scores for all participants, with a baseline mean score of 7.2 and a follow-up mean score of 7.1 $299(\mathrm{t}(26)=0.26 ; \mathrm{p}$-value $=0.80)$. The in-person and web-based groups also had statistically 300 insignificant decreases in mean group scores for self-efficacy, as demonstrated in table 2 . The 301 Diabetes Distress Scale demonstrated decreased distress overall, from a mean at baseline of 2.5 302 to a follow-up mean of $2.0(\mathrm{t}(26)=2.6$; $\mathrm{p}$-value=0.02), and in each of the four dimensions it 303 assesses; emotional burden, regimen distress, physician distress, and interpersonal distress. The 304 physician distress and interpersonal distress did not have statistically significant differences 305 between baseline and follow-up mean scores. The emotional burden dimension had a statistically 306 significant decrease in mean scores, with a baseline mean score of 2.9 and a follow-up mean 
307 score of $2.3(\mathrm{t}(26)=2.6$; $\mathrm{p}$-value=0.02). In-person participants also had a statistically significant

308 decrease in emotional burden mean scores, as demonstrated in table 2 . The regimen distress

309 dimension had a statistically significant decrease in mean scores, with a baseline mean score of

3103.1 and a follow-up mean score of $2.6(\mathrm{t}(26)=2.6 ; \mathrm{p}$-value=0.02). The web-based group also had

311 a statistically significant decrease in regimen distress mean scores, as shown in table 2 . The

312 Generalized Anxiety Disorder Scale had a statistically significant decrease in anxiety from mild

313 anxiety to low anxiety for all participants, with a mean baseline score of 6.3 and a follow-up

314 mean score of $4.2(\mathrm{t}(26)=2.2 ; \mathrm{p}$-value=0.04). The Generalized Anxiety Scale did not yield

315 statistically significant differences in the in-person and web-based groups, as demonstrated in

316 table 2. Depression, as assessed by the PHQ-9 questionnaire, decreased by the end of the study

317 but was not statistically significant for the study cohort and each intervention group (table 2).

318 Similarly, there was a statistically insignificant decrease in perceived stress levels in the study, as

319 assessed by the Perceived Stress Scale (table 2). More specifically, the in-person group had an

320 increase in perceived stress (13.3 to 15.4) while the web format participants had a decrease in

321 perceived stress (17.0 to 13.6$)$. The only HRQoL domain of the RAND-36 survey that

322 demonstrated a statistically significant increase was the pain health concept. A statistically

323 significant increase for this health concept was demonstrated for participants overall as well as

324 the in-person group. The overall mean score increased from 51 at baseline to 70 at follow-up

$325(\mathrm{t}(26)=-3.8 ; \mathrm{p}$-value $=0.002)$, and the in-person group mean score increased from 39 at baseline

326 to 64 at follow-up $(\mathrm{t}(26)=-0.28$; $\mathrm{p}$-value $=0.01)$. Most of the remaining health concepts had

327 increased mean scores from baseline to follow-up assessments, although these differences were

328 not statistically significant (table 2). In the paired t-test analyses, participant mean HbA1c

329 improved from $8.5 \%$ at baseline to $7.7 \%$ during follow-up $(\mathrm{t}(26)=0.4$, p-value $=0.08)($ table 2$)$. 
331 Qualitative results:

332 Themes identified from the qualitative data included: (1) intervention group social support

333 through information sharing; (2) mental health and personal identities in diabetes understanding

334 and management; (3) receptivity to CBT/MI Intervention positively impacts self-efficacy

335 through improved health literacy.

337 Intervention Group Social Support Through Information Sharing: Participants in both

338 intervention formats emphasized the importance of participating in the intervention as a means of

339 social support which required intentional engagement with the intervention materials and

340 between participants of the intervention. Two general ideas were expressed pervasively in the

341 transcripts: 1) participants benefit most by sharing and receiving information 2) participants were

342 reassured by knowing that they were not alone in treating their diabetes. For this thematic thread,

343 social support and information sharing was linked to interactions within study groups but did not

344 extend outside of the group. Reflections of the participants demonstrated perceptions of the

345 importance of being open to the experiences of others and that day-to-day behaviors could be

346 influenced by the information learned from group interactions. In seeking support from focus

347 group members, the sentiment that participants were in a community where they could be

348 understood was an important thematic thread. Participants were reassured by the communal

349 experience of navigating diabetes management with others also inspired by the success they

350 shared as a group. This sentiment was clearly expressed by one participant who stated, "I hear

351 [somebody's] victory so that encourages me." The sense of belonging mirrored the effect of

352 information sharing, as participants were willing to adjust behaviors to improve diabetes 
353 management. The support gained from a shared experience spurred participant to treat their

354 diabetes in novel ways with the new information gained. Participants were in a space where they

355 felt comfortable enough to honestly share instances of unhealthy behaviors, which illustrates the

356 supportive environment that was promoted by the CBT/MI intervention. Instead of being

357 criticized by fellow group members for admitting unhealthy behaviors, participants were instead

358 encouraged to "do it in moderation." Promoting moderation as a mechanism for more sustainable

359 behavioral change was often mentioned in the transcripts and encouraged among participants to

360 limit the intake of unhealthy foods. The community formed by study participants also provided

361 study group members with accountability and positive reinforcement. One participant stated, "I

362 know I was [going to] feel accountable when we had the meeting [...] it definitely inspired me to

363 do better," clearly demonstrating the promotion of sustained behavioral change due to group

364 accountability. The code map that illustrates the visuospatial relation of the codes which

365 informed this thematic thread can be found in figure 3.

367 Mental Health and Personal Identities in Diabetes Understanding and Management: Study

368 participants emphasized that the stresses associated with being AA or Black were unique. One

369 participant stated, "African Americans may have some life stressors that other classes may not

370 have." Identifying the stressors associated with race was an important step in understanding

371 underlying influences that contribute to effective behavioral changes. Race was not the only

372 pertinent identity that participants discussed in relation to diabetes management. One participant

373 discussed how costs associated with proper diabetes management was linked to socioeconomic

374 position when he stated, "The whole management $[\ldots]$ between medications and equipment [...]

$375[\ldots]$ in terms of healthy eating [...] It can become taxing on the pocketbook." The costs associated 
376 with proper diabetes management can impact beneficial behavioral changes when considering

377 SES. Participant mental health also impacted their perception of diabetes. The mental health

378 challenges of managing diabetes were shown to be linked to a lack of effective strategies of

379 managing diabetes with reflections of how the CBT/MI intervention improved management

380 techniques. Their reflections demonstrated that mental health was negatively impacted by having

381 diabetes, which improved with the CBT/MI intervention. Having a social network of people

382 living with diabetes contributed positively to their outlook on diabetes management as this

383 provided an outlet of negative emotions and an improved perspective of diabetes. Ultimately, a

384 participant's reflection revealed that "the intervention [...] made me realize that I wasn't the only

385 one," emphasizing the importance of having a community to lean on. The code map that

386 illustrates the visuospatial relation of the codes which informed this thematic thread can be found

387 in figure 4.

Receptivity to CBT/MI Intervention Positively Impacts Self-Efficacy through Improved Health

389 Literacy: Receptivity captured the positive dimensions of how study participants received study

390 materials. The sentiment that positive reception was essential to a more successful participation

391 experience was shared by many study participants. The positive reception of study materials with

392 an improved outlook on living with diabetes resulted in participants retaining health information

393 thus improving health literacy. Improved health literacy was most readily observed when a

394 participant said, "You can go at it a different route, cause now you have more knowledge about

395 what you're dealing with", identifying the benefit of health literacy to diabetes management. As

396 a result, participant self-efficacy improved as they accepted and applied the knowledge shared

397 with them. The intervention also increased awareness to life stressors to promote healthy coping

398 strategies beneficial to diabetes management, thus providing another mechanism to maintain a 
399 positive outlook; informed decision making. There was a cyclical trend of the positive reception

400 of information which allowed participants to retain the learned information to be self-efficacious

401 and apply it toward positive health outcomes. Per their reflections, participants were able to

402 "recognize the problem [...] apply those things they learned," and were "prepared to deal with

403 the situation" following the CBT/MI intervention. The code map that illustrates the visuospatial

404 relation of the codes which informed this thematic thread can be found in figure 5.

406 Discussion:

407 This study evaluated the feasibility and acceptability of a cognitive behavior therapy intervention 408 among African American patients with type-2 Diabetes mellitus. It additionally explored the 409 experiences of African Americans with type 2 diabetes and captured their perspectives 410 concerning Culturally Tailored CBT/MI as an intervention technique in managing their diabetes.

411 An analysis was performed to determine how the intervention was received by participants and

412 quantitative baseline and follow-up data was analyzed to determine if positive or negative

413 perceptions were supported by health-related assessment tools. The study was conducted by

414 independently assessing qualitative and quantitative data to gain an understanding of the

415 implications CBT/MI interventions have for Black or African American people in the U.S. A

416 grounded theory approach allowed the study team to explore how the information gleaned from

417 the independent analysis of the quantitative and qualitative data could better inform study

418 findings when considered concurrently. Results of the concurrent analysis illuminated two core

419 concepts: 1) disease perception and perspectives on quality of life are interrelated 2) social

420 support gained from CBT/MI interventions relate to perceived distress associated with diabetes

421 management. This concurrent analysis revealed that a group-based CBT/MI intervention for type 
4222 DM care was feasible, acceptable, and positively received by AA participants. There were

423 benefits of social support through group interactions and a stronger sense of self-efficacy due to

424 health education.

425

426 Core Concept: Quality of Life and Disease Perceptions

427 Participants reported increased mean scores, from baseline to follow-up assessments, in seven of 428 the eight health concepts of the HRQoL scale. The concept of pain had a statistically significant 429 increase, during follow-up, for the overall group and the in-person intervention group. This is 430 indicative of more positive perceptions of HRQoL in relation to pain associated with DM. The

431 RAND-36 Emotional problems/ limitations health concept is the only HRQoL health concept to 432 differentially demonstrate decreased HRQoL overall and in both intervention groups. When 433 coupled with the results of the depression scale there exists a congruence in the observed trend in

434 which participants have decreased health-related emotional capacity with mild levels of 435 depression. These mixed results for HRQoL were particularly intriguing and warranted further 436 consideration.

437 Concurrent analysis of the data emphasized the importance of considering how the unique 438 stresses of being AA, expressed in the qualitative data, interacts with the quantitative mental 439 health and HRQoL data. Participant awareness of their daily stresses, influenced by their racial 440 identity, assisted in developing coping mechanisms that aid in diabetes management and may 441 improve their perceived HRQoL. Awareness of these stresses may conversely lead to cynicism 442 that can contribute to other mental health concerns and perception of decreased HRQoL. The 443 literature emphasizes that diabetes-related distress and depression can contribute to low glycemic 444 control, treatment adherence behaviors and self-management (15-17). However, research on 
445 social networks and diabetes management has shown that the quality of an individual's social

446 network could be an indicator of improved health outcomes in diabetes management (33). The

447 qualitative data indicated that providing a space with social support which disseminated pertinent

448 health information could mitigate the mental health difficulties participants faced. Therefore, the

449 community created in the respective intervention groups may have been beneficial to participant

450 health outcomes during the study.

451 Sociological factors are also essential in holistically considering disparate health outcomes for

452 AA adults with type 2 diabetes. Self-reported experiences of racial discrimination have been

453 associated with poorer health outcomes in type 2 diabetes (13). The effects of SES have also

454 been shown to be associated with the prevalence of type 2 diabetes in the AA community (14).

455 The literature cites a strong inverse relationship between SES and diabetes incidence, citing that

456 as income and educational level decrease the diabetes risk increases two-fold (34). Therefore,

457 sociological factors independent of patient behavior may contribute to poor health outcomes. By

458 gaining a better understanding of life stressors associated with their race and socioeconomic

459 position, participants were able to develop better coping strategies to manage their diabetes,

460 further facilitated by their open-mindedness to behavioral change. The study's qualitative data

461 demonstrated the importance of SES in considering the costs associated with proper diabetes

462 management. The associated additional costs result in higher levels of stress due to the added

463 financial burden of diabetes care. The interaction of participant identities and stress when

464 considering behavioral change to improve diabetes outcomes was identified as a quintessential

465 aspect of understanding the perspectives of AA patients. 
466 As a group, participants held each other accountable to improve diabetes management while

467 bolstering mental health support in the community that participants created with one another.

468 The intervention offered participants a skillset to cope with the stress of diabetes management

469 and have an active role in improving their quality of life. While there may have been an

470 improved outlook on disease management, the stresses associated with daily diabetes

471 management for an AA person may still contribute to a decreased emotional capacity to cope

472 with diabetes in terms of mental health. Finding a community of support may help with the

473 diminished emotional capacity observed in the study.

475 Core Concept: Emotional Burden, Distress \& Social Network Support

476 The DDS demonstrated decreased distress overall and in each of the scale's four dimensions:

477 Emotional Burden, Physician Distress, Regimen Distress, and Interpersonal distress. Emotional

478 Burden and Regimen Distress had scores greater than or equal to the clinically meaningful

479 threshold of 3 at baseline and, subsequent scores that decreased to levels below this threshold.

480 These results suggest that the CBT/MI intervention appeared to lower distress associated with

481 the diabetes management regimen, which could be more effective on a web-based platform.

482 Similarly, the intervention may be beneficial in alleviating distress associated with the emotional

483 burden of diabetes, more so in an in-person setting.

484 It is important to note that a major documented comorbid factor to diabetes is depression. Studies

485 have shown that depression and diabetes are likely to occur together twice as frequently as would 486 be predicted simply by chance (10). The incidence of depression has also been documented to be $48724 \%$ higher in people with diabetes (35). Not only are diabetes and depression more like to occur 488 together, but they have also been shown to exacerbate symptoms. Epidemiological studies have 
489 demonstrated that the association between the two illnesses is bidirectional, which means that

490 diabetes can impact the patient's psychological well- being while depression can impact the

491 severity of diabetes symptoms $(36,37)$. More specifically, people with diabetes have longer

492 lasting depressive episodes that occur more often than those in the general population (3). The

493 group-based design of the CBT/MI intervention was beneficial to patients who experienced the

494 comorbid effects of diabetes and depression by providing a space to promote proper diabetes

495 management and social support. The Mental Health, Personal Identities and Diabetes

496 Management theme revealed that participants had positive outlooks when in a social network of

497 similar experiences. Group members demonstrated a level of comfort such that, they shared

498 unhealthy eating behaviors. In turn, the group's response was to approach diabetes treatment

499 with a mindset of moderation, which was crucial in supporting participants.

500 Positive reinforcement and group accountability fostered candid conversations among group

501 members and enabled participants to build a social support system. Health literacy disparities

502 were addressed through provision of health information from a trained health professional.

503 Participant receptivity of study material was essential in addressing disparities in health literacy.

504 An integrative review of the self-management of type 2 diabetes indicated that the perspectives

505 and participation of patients is vital in the continued success of properly treating type 2 diabetes

506 (38). The participants' willingness to learn and apply study information allowed them to retain

507 the CBT/MI intervention to bolster their self-efficacy. Past research has also shown that

508 combining medical nutrition therapy and self-management education improved patient outcomes

509 with significant weight loss, HbA1c reduction, and a decrease in cholesterol levels (39). Further

510 research exploring the impact of diabetes self-management education demonstrated improved

511 self-care, improved self-efficacy and lower levels of psychological distress (40). AA participants 
512 also demonstrated better health status with their improved psychological distress (40). Therefore,

513 promoting self-efficacy through this CBT/MI intervention was an appropriate approach to

514 address the psychological distress associated with diabetes management.

515 Group member accountability and participant receptivity may have contributed to the decreased

516 regimen distress observed in this setting of social support. Creating a communal component to

517 diabetes management may be an effective method to improving the outlook of AA adults and

518 mitigate the associated distress stemming from living with diabetes as a member of this racial

519 group.

520

521 Strengths and Limitations: The study had a number of strengths. It presented a novel approach of

522 provision of CBT/MI in two forms- an in-person format and a web-based format which has not

523 been attempted previously. The study addressed a significant gap in existing literatures by

524 explicitly considering the perspectives of AA adults in chronic disease management. The study

525 revealed unique aspects of health education and chronic disease management through the

$526 \mathrm{CBT} / \mathrm{MI}$ intervention, to aid participants in promoting positive health outcomes. The study

527 provided participants knowledge about psychological, behavioral, psychosocial, and social

528 determinants of health for a more holistic treatment plan. Participants were empowered through

529 information sharing and in finding social support among other study participants.

530 Our study was a pilot study but experienced loss to follow-up, potentially resulting in selection

531 bias. This may affect the depth and richness of the data collected through the focus group

532 discussions. Participants were provided the surveys to fill out on their own and assured

533 anonymity. However, there is still a possibility that the self-reported data may have social

534 desirability bias as they related to concepts of mental health, which is often stigmatized. 
535 Hemoglobin A1C was measured for a few participants using a point of care test which may have

536 introduced measurement error. While the difference in mean hemoglobin A1C scores was not

537 significant, the data does indicate some promise for future studies. The information from focus

538 groups may have come from participants who are more likely to actively engage with the study

539 and may have resulted in an unintentional bias to be introduced toward more positive reflections.

\section{Conclusion:}

542 The study demonstrated that CBT/MI based group intervention was feasible and acceptable in

543 AA with uncontrolled type 2 diabetes. A CBT/MI based group intervention led to positive

544 changes in glycemic control (change in HbA1c from $8.5 \%$ to $7.7 \%$ ), distress and anxiety

545 associated with diabetes mellitus. Our focus group analyses showed the benefits of social support

546 through intervention group interactions, and a stronger sense of participant self-efficacy due to

547 health education and information sharing, Study results supported prior findings that

548 mental/psychological health is an important factor in diabetes treatment and management,

549 supporting the idea that diabetes is a multifactorial disease. Given the complex array of

550 interacting components to diabetes, a more comprehensive treatment plan, like CBT/MI, may be

551 useful in promoting healthy diabetes self-management. Future studies should consider expanding

552 the study's sampling frame to include a wider range of the AA population and similar tailored

553 interventions targeting other marginalized groups. This approach would diversify the lived

554 experiences of participants and provide more robust data to better understand how to support

555 diabetes management in the AA community. 
559 List of Abbreviations:

560 African American (AA)

561 Diabetes mellitus (DM)

562 Cognitive behavioral therapy (CBT)

563 Motivational Interviewing (MI)

564 Glycosylated hemoglobin (HbA1c)

565 Socioeconomic status (SES)

566 Body Mass Index (BMI)

567 Generalized Anxiety Disorder (GAD)

568 Patient Health Questionnaire (PHQ)-9 (PHQ-9)

569 Perceived Stress Scale (PSS)

570 Health-Related Quality of Life (HRQoL)

571 Focus group discussion (FGD)

572

573

574

575

576 


\section{Declarations}

580 All manuscripts must contain the following sections under the heading 'Declarations':

- Ethics approval and consent to participate: This study was reviewed and approved by the Institutional Review Board, Emory University. Participation in the study was voluntary and informed consent was obtained from all participants, prior to participation.

584 - Consent for publication: Not applicable

585 - Availability of data and materials: Data can be made available on request, pending 586 institutional and funding agency guidelines.

587 - Competing interests: No competing interests.

588 - Funding: This work was supported by P30DK111024,Georgia Diabetes Translation Research

$589 \quad$ Center

590 - Authors' contributions: RC performed the analysis and drafted the manuscript. VS drafted

591 and reviewed the manuscript. RM reviewed and provided critical feedback on the

592 manuscript. AO designed the intervention and supervised its implementation. AK is the

593 principal investigator and supervised the design and conduct of the study.

594 - Acknowledgements: The authors thank all the study participants for their time and 595 participation in this study. We would also like to thank Dr Francisco Pasquel for his 596 suggestions to improve the readability of the abstract. 


\section{References:}

1. Prevention CfDCa. National Diabetes Statistics Report, 20202020 [updated Aug 28, 2020. Available from: https://www.cdc.gov/diabetes/data/statistics-report/index.html

2. Relations CM. Diabetes: African American Health Disparities 2003 [Available from: https://www.cdc.gov/media/presskits/aahd/diabetes.htm.

3. Chatterjee R, Maruthur NM, Edelman D. Novel risk factors for type 2 diabetes in African-Americans. Current diabetes reports. 2015;15(12):1-10.

4. Health USDoHaHSOoM. Diabetes and African Americans 2021 [updated 03/1/2021. Available from: https://minorityhealth.hhs.gov/omh/browse.aspx?lvl=4\&lvlid=18

5. De Rekeneire N, Rooks RN, Simonsick EM, Shorr RI, Kuller LH, Schwartz AV, et al. Racial differences in glycemic control in a well-functioning older diabetic population: findings from the Health, Aging and Body Composition Study. Diabetes care. 2003;26(7):1986-92. 6. Karter AJ. Race and ethnicity: vital constructs for diabetes research. Diabetes Care. 2003;26(7):2189-93.

7. Heisler M, Smith DM, Hayward RA, Krein SL, Kerr EA. Racial disparities in diabetes care processes, outcomes, and treatment intensity. Medical care. 2003:1221-32.

8. Health USDoHaHSOoM. Obesity and African Americans 2020 [updated 03/26/2020. Available from: https://www.minorityhealth.hhs.gov/omh/browse.aspx?lvl=4\&lvlID=25

9. Barnard K, Skinner T, Peveler R. The prevalence of co-morbid depression in adults with Type 1 diabetes: systematic literature review. Diabetic medicine. 2006;23(4):445-8. 10. Anderson RJ, Freedland KE, Clouse RE, Lustman PJ. The prevalence of comorbid depression in adults with diabetes: a meta-analysis. Diabetes care. 2001;24(6):1069-78.

11. Grigsby AB, Anderson RJ, Freedland KE, Clouse RE, Lustman PJ. Prevalence of anxiety in adults with diabetes: a systematic review. Journal of psychosomatic research. 2002;53(6):1053-60.

12. Balhara YPS. Diabetes and psychiatric disorders. Indian journal of endocrinology and metabolism. 2011;15(4):274.

13. Peek ME, Wagner J, Tang H, Baker DC, Chin MH. Self-reported racial/ethnic discrimination in healthcare and diabetes outcomes. Medical care. 2011;49(7):618. 14. Robbins JM, Vaccarino V, Zhang H, Kasl SV. Socioeconomic status and type 2 diabetes in African American and non-Hispanic white women and men: evidence from the Third National Health and Nutrition Examination Survey. American journal of public health. 2001;91(1):76. 15. Safren SA, Gonzalez JS, Wexler DJ, Psaros C, Delahanty LM, Blashill AJ, et al. A randomized controlled trial of cognitive behavioral therapy for adherence and depression (CBTAD) in patients with uncontrolled type 2 diabetes. Diabetes care. 2014;37(3):625-33. 16. Cummings DM, Lutes LD, Littlewood K, Solar C, Carraway M, Kirian K, et al. Randomized trial of a tailored cognitive behavioral intervention in type 2 diabetes with comorbid depressive and/or regimen-related distress symptoms: 12-month outcomes from COMRADE. Diabetes Care. 2019;42(5):841-8.

17. Uchendu C, Blake H. Effectiveness of cognitive-behavioural therapy on glycaemic control and psychological outcomes in adults with diabetes mellitus: a systematic review and meta-analysis of randomized controlled trials. Diabetic Medicine. 2017;34(3):328-39.

18. Yang X, Li Z, Sun J. Effects of Cognitive Behavioral Therapy-Based Intervention on Improving Glycaemic, Psychological, and Physiological Outcomes in Adult Patients With 
Diabetes Mellitus: A Meta-Analysis of Randomized Controlled Trials. Frontiers in psychiatry. 2020;11:711.

19. Helbig S, Fehm L. Problems with homework in CBT: Rare exception or rather frequent? Behavioural and cognitive psychotherapy. 2004;32(3):291-301.

20. Moyers T, Manuel J, Ernst D, Moyers T, Manuel J, Ernst D, et al. Motivational interviewing treatment integrity coding manual 4.1 (MITI 4.1). Unpublished manual. 2014. 21. Hall GCN, Yip T, Zárate MA. On becoming multicultural in a monocultural research world: A conceptual approach to studying ethnocultural diversity. American Psychologist. 2016;71(1):40.

22. Griner D, Smith TB. Culturally adapted mental health intervention: A meta-analytic review. Psychotherapy: Theory, research, practice, training. 2006;43(4):531.

23. Sue DW, Capodilupo CM, Torino GC, Bucceri JM, Holder A, Nadal KL, et al. Racial microaggressions in everyday life: implications for clinical practice. American psychologist. 2007;62(4):271.

24. Center S-MR. Self-Efficacy for Diabetes [Available from: https://www.selfmanagementresource.com/docs/pdfs/English - self-efficacy diabetes.pdf 25. Polonsky WH, Fisher L, Earles J, Dudl RJ, Lees J, Mullan J, et al. Assessing psychosocial distress in diabetes: development of the diabetes distress scale. Diabetes care. 2005;28(3):626-31.

26. Spitzer RL, Kroenke K, Williams JB, Löwe B. A brief measure for assessing generalized anxiety disorder: the GAD-7. Archives of internal medicine. 2006;166(10):1092-7.

27. Kroenke K, Spitzer RL, Williams JB. The PHQ-9: validity of a brief depression severity measure. Journal of general internal medicine. 2001;16(9):606-13.

28. Cohen S, Kamarck T, Mermelstein R. Perceived stress scale. Measuring stress: A guide for health and social scientists. 1994;10:1-2.

29. Hays RD, Morales LS. The RAND-36 measure of health-related quality of life. Annals of medicine. 2001;33(5):350-7.

30. Nasreddine ZS, Phillips NA, Bédirian V, Charbonneau S, Whitehead V, Collin I, et al. The Montreal Cognitive Assessment, MoCA: a brief screening tool for mild cognitive impairment. Journal of the American Geriatrics Society. 2005;53(4):695-9.

31. Rogers EM. Diffusion of preventive innovations. Addictive behaviors. 2002;27(6):98993.

32. Rogers E. Diffusion of innovations. Hohenheim. Germany. Simon and Schuster; 2010. 33. Shaya FT, Chirikov VV, Howard D, Foster C, Costas J, Snitker S, et al. Effect of social networks intervention in type 2 diabetes: a partial randomised study. J Epidemiol Community Health. 2014;68(4):326-32.

34. Whittemore R, Melkus GDE, Grey M. Applying the social ecological theory to type 2 diabetes prevention and management. Journal of Community Health Nursing. 2004;21(2):87-99. 35. Nouwen A, Winkley K, Twisk J, Lloyd CE, Peyrot M, Ismail K, et al. Type 2 diabetes mellitus as a risk factor for the onset of depression: a systematic review and meta-analysis. Diabetologia. 2010;53(12):2480-6.

36. Golden SH, Lazo M, Carnethon M, Bertoni AG, Schreiner PJ, Roux AVD, et al. Examining a bidirectional association between depressive symptoms and diabetes. Jama. 2008;299(23):2751-9.

37. Holt RI, De Groot M, Golden SH. Diabetes and depression. Current diabetes reports. 2014;14(6):1-9. 
694 38. Carpenter R, DiChiacchio T, Barker K. Interventions for self-management of type 2 695 diabetes: An integrative review. International journal of nursing sciences. 2019;6(1):70-91. 696 39. Marincic PZ, Hardin A, Salazar MV, Scott S, Fan SX, Gaillard PR. Diabetes self697 management education and medical nutrition therapy improve patient outcomes: a pilot study 698 documenting the efficacy of registered dietitian nutritionist interventions through retrospective 699 chart review. Journal of the Academy of Nutrition and Dietetics. 2017;117(8):1254-64.

700 40. Peña-Purcell N, Han G, Smith ML, Peterson R, Ory MG. Impact of diabetes self701 management education on psychological distress and health outcomes among African Americans 702 and Hispanics/Latinos with diabetes. Diabetes Spectrum. 2019;32(4):368-77. 
Figure 1: Participant flow diagram

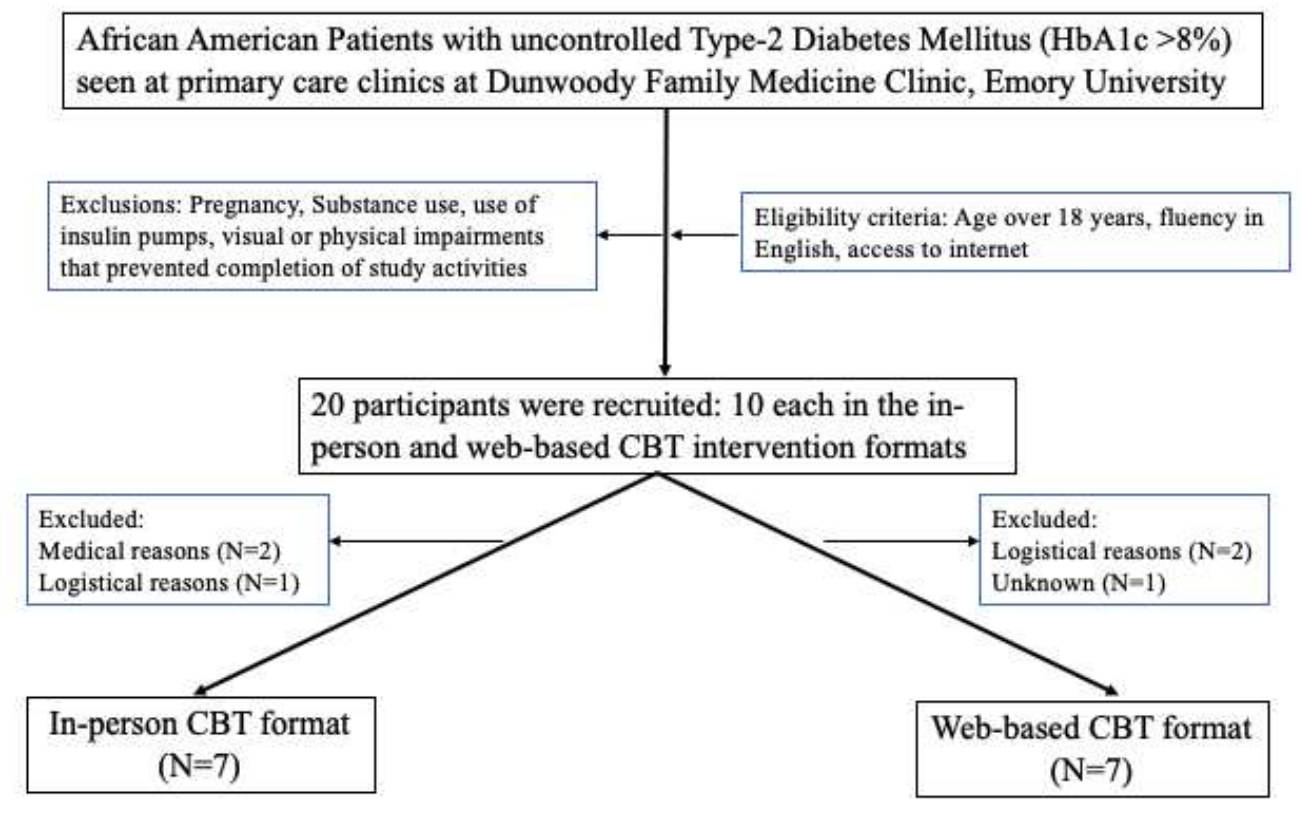


Figure 2: Preliminary Code Map for Qualitative Analysis (Code Map 1)

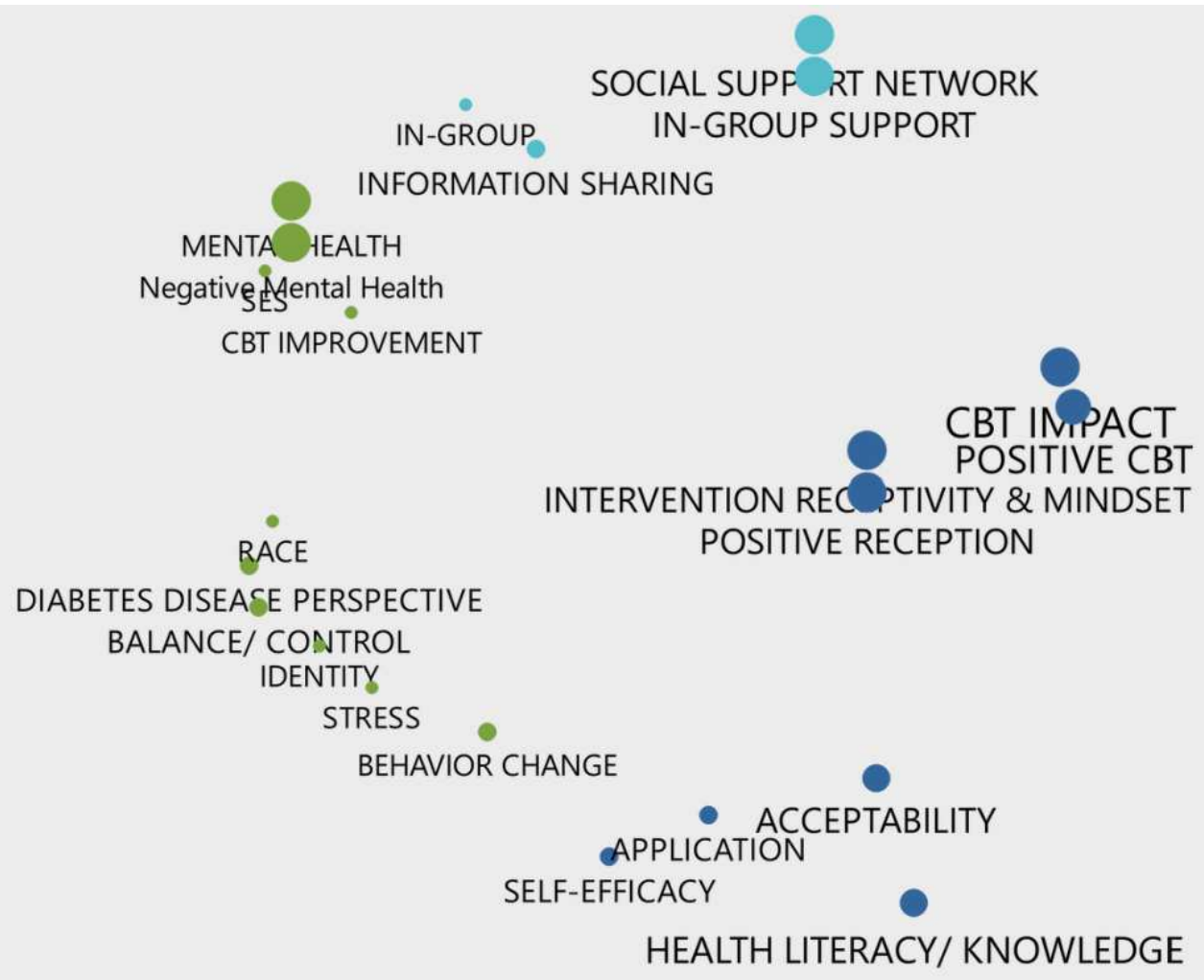


Figure 3: Social Support and Information Sharing (Code Map 2)

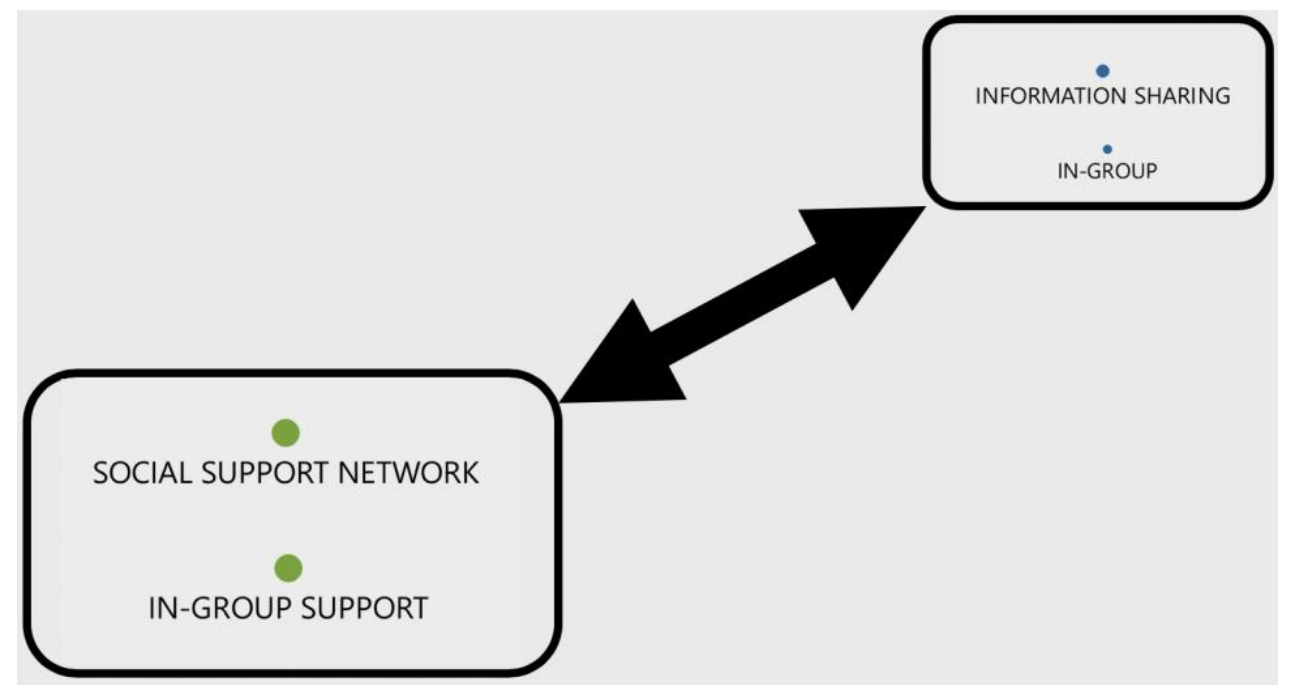


Figure 4: Disease Perception, Mental Health and Identities (Code Map 3)

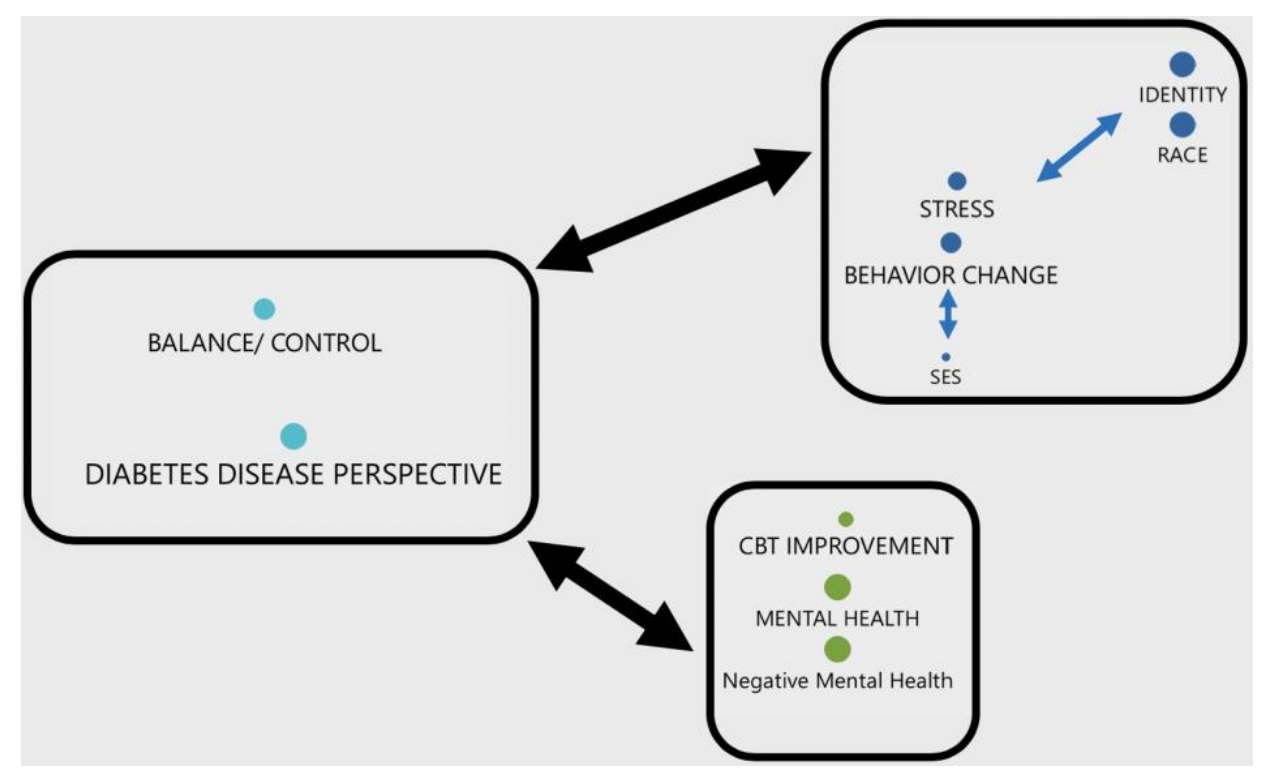


Figure 5: Receptivity, Impact and Health Literacy (Code Map 4)

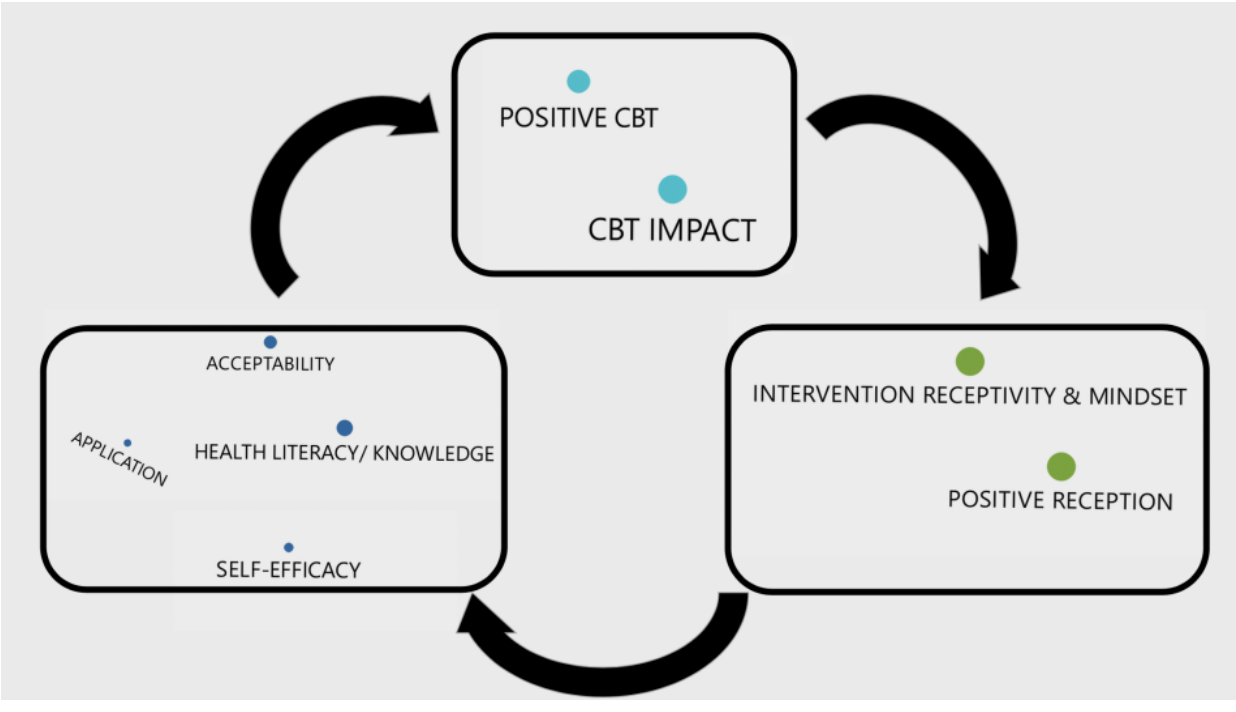


Table 1: Participant characteristics at study baseline $(\mathrm{N}=14)$

\begin{tabular}{|c|c|c|c|c|c|c|c|c|c|c|c|c|c|}
\hline \multirow[b]{2}{*}{ Characteristic } & \multirow[b]{2}{*}{ Category } & \multirow{2}{*}{\begin{tabular}{|c|}
$\begin{array}{c}\text { Frequency } \\
(\mathbf{N})\end{array}$ \\
All \\
Participants
\end{tabular}} & \multirow{2}{*}{$\begin{array}{c}\begin{array}{c}\text { Percent } \\
(\%)\end{array} \\
\text { All } \\
\text { Participants } \\
\end{array}$} & \multirow{2}{*}{$\begin{array}{c}\text { Mean } \\
\text { All } \\
\text { Participants }\end{array}$} & \multicolumn{2}{|c|}{$\begin{array}{c}\text { Frequency (N) } \\
\text { By Group }\end{array}$} & \multicolumn{2}{|c|}{$\begin{array}{l}\text { Percent (\%) } \\
\text { By Group }\end{array}$} & \multicolumn{2}{|c|}{ Mean } & \multirow{2}{*}{$\begin{array}{c}\text { Standard } \\
\text { Error } \\
\text { (In-Person/ } \\
\text { Web) }\end{array}$} & \multirow{2}{*}{$\begin{array}{c}\text { 95\% CI } \\
\text { (In-Person// } \\
\text { Online) }\end{array}$} & \multirow{2}{*}{$\begin{array}{c}\text { P-value } \\
\text { (In-Person/ } \\
\text { web) }\end{array}$} \\
\hline & & & & & $\begin{array}{c}\text { In- } \\
\text { Person }\end{array}$ & Web & $\begin{array}{c}\text { In- } \\
\text { Person }\end{array}$ & Web & $\begin{array}{c}\text { In- } \\
\text { Person }\end{array}$ & Web & & & \\
\hline \multirow{2}{*}{ Age (Years) } & $>55$ & 5 & 36 & \multirow{2}{*}{56.43} & 4 & 1 & 57 & 14 & \multirow{2}{*}{52} & \multirow{2}{*}{60.86} & \multirow{2}{*}{4.53} & \multirow{2}{*}{$(-0.98,18.78)$} & \multirow{2}{*}{0.07} \\
\hline & $55+$ & 9 & 64 & & 3 & 6 & 43 & 86 & & & & & \\
\hline \multirow{4}{*}{$\begin{array}{l}\text { Number of } \\
\text { Years with } \\
\text { Diabetes }\end{array}$} & $0->5$ & 2 & 14 & \multirow{4}{*}{13.30} & 0 & 2 & 0 & 29 & \multirow{4}{*}{14.86} & \multirow{4}{*}{11.5} & \multirow{4}{*}{2.82} & \multirow{4}{*}{$(-9.51,2.80)$} & \multirow{4}{*}{0.26} \\
\hline & $6->10$ & 2 & 14 & & 1 & 1 & 14 & 14 & & & & & \\
\hline & $11->15$ & 5 & 36 & & 3 & 2 & 43 & 29 & & & & & \\
\hline & $20->25$ & 1 & 7 & & 1 & 0 & 14 & 0 & & & & & \\
\hline \multirow{3}{*}{ Weight Status } & $\begin{array}{c}\text { Normal } \\
\text { (BMI 18.5-24.9) } \\
\end{array}$ & 2 & 14 & \multirow{3}{*}{33.42} & 1 & 1 & 14 & 14 & \multirow{3}{*}{35.77} & \multirow{3}{*}{31.07} & \multirow{3}{*}{4.39} & \multirow{3}{*}{$(-14.26,4.86)$} & \multirow{3}{*}{0.31} \\
\hline & $\begin{array}{c}\text { Overweight } \\
\text { (BMI 25.0-29.9) }\end{array}$ & 3 & 21 & & 1 & 2 & 14 & 29 & & & & & \\
\hline & $\begin{array}{c}\text { Obese } \\
(\mathrm{BMI}>=30.0)\end{array}$ & 9 & 64 & & 5 & 4 & 71 & 57 & & & & & \\
\hline \multirow{2}{*}{ Gender } & Man & 3 & 21 & (-) & 2 & 1 & 29 & 14 & (-) & $(-)$ & (-) & (-) & (-) \\
\hline & Woman & 11 & 79 & (-) & 5 & 6 & 71 & 86 & (-) & (-) & (-) & $(-)$ & $(-)$ \\
\hline Status & Married & 4 & 29 & $(-)$ & 1 & 3 & 14 & 43 & $(-)$ & $(-)$ & $(-)$ & $(-)$ & $(-)$ \\
\hline & Divorced & 3 & 21 & & 2 & 1 & 29 & 14 & & & & & \\
\hline Highest Level & $\begin{array}{c}\text { Less than a } \\
\text { college degree }\end{array}$ & 7 & 50 & & 3 & 4 & 43 & 57 & & & & & \\
\hline of Education & $\begin{array}{l}\text { College Degree or } \\
\text { More }\end{array}$ & 7 & 50 & $(-)$ & 4 & 3 & 57 & 43 & $(-)$ & $(-)$ & $(-)$ & $(-)$ & $(-)$ \\
\hline
\end{tabular}

Abbreviations: BMI: body mass index, CI: confidence interval 
Table 2: Quantitative scales score- pre (baseline) and post (follow-up) cognitive behavioral therapy intervention

\begin{tabular}{|c|c|c|c|c|c|}
\hline Scales & $\begin{array}{l}\text { T2DM Mean at } \\
\text { Baseline }\end{array}$ & $\begin{array}{l}\text { T2DM Mean at } \\
\text { Follow-Up }\end{array}$ & $t(26)$ & P-value & $\begin{array}{c}\text { Max } \\
\text { Score }\end{array}$ \\
\hline $\begin{array}{l}\text { SMRC Self-Efficacy } \\
\text { All Participants }(n=14) \\
\text { In-Person }(n=7) \\
\text { Online }(n=7)\end{array}$ & $\begin{array}{l}7.21 \\
7.34 \\
6.94 \\
\end{array}$ & $\begin{array}{l}7.10 \\
7.43 \\
6.77 \\
\end{array}$ & \begin{tabular}{|c}
0.26 \\
-0.16 \\
0.47 \\
\end{tabular} & $\begin{array}{l}0.80 \\
0.88 \\
0.65 \\
\end{array}$ & 10 \\
\hline $\begin{array}{l}\text { DDS Total } \\
\text { All Participants }(\mathrm{n}=14) \\
\text { In-Person }(\mathrm{n}=7) \\
\text { Online }(\mathrm{n}=7)\end{array}$ & $\begin{array}{l}2.46 \\
2.35 \\
2.57\end{array}$ & $\begin{array}{l}1.95 \\
1.74 \\
2.15\end{array}$ & \begin{tabular}{|l|}
2.62 \\
1.98 \\
1.60
\end{tabular} & $\begin{array}{c}0.02 * \\
0.09 \\
0.16\end{array}$ & 6 \\
\hline $\begin{array}{l}\text { DDS- Emotional Burden } \\
\text { All Participants }(n=14) \\
\text { In-Person }(n=7) \\
\text { Online }(n=7) \\
\end{array}$ & $\begin{array}{l}2.94 \\
3.00 \\
2.89 \\
\end{array}$ & $\begin{array}{l}2.28 \\
2.00 \\
2.56\end{array}$ & \begin{tabular}{|l|}
2.59 \\
2.66 \\
1.00 \\
\end{tabular} & $\begin{array}{c}0.02 * \\
0.04 * \\
0.35\end{array}$ & 6 \\
\hline $\begin{array}{l}\text { DDS- Physician Distress } \\
\text { All Participants }(n=14) \\
\text { In-Person }(n=7) \\
\text { Online }(n=7)\end{array}$ & $\begin{array}{l}1.70 \\
1.39 \\
2.00 \\
\end{array}$ & $\begin{array}{l}1.14 \\
1.07 \\
1.21 \\
\end{array}$ & \begin{tabular}{|l|}
1.80 \\
1.12 \\
1.42 \\
\end{tabular} & $\begin{array}{l}0.09 \\
0.31 \\
0.21 \\
\end{array}$ & 6 \\
\hline $\begin{array}{l}\text { DDS- Regimen Distress } \\
\text { All Participants }(\mathrm{n}=14) \\
\text { In-Person }(\mathrm{n}=7) \\
\text { Online }(\mathrm{n}=7)\end{array}$ & $\begin{array}{l}3.11 \\
2.71 \\
3.51 \\
\end{array}$ & $\begin{array}{l}2.55 \\
2.11 \\
2.99 \\
\end{array}$ & \begin{tabular}{|c|}
2.6 \\
1.47 \\
2.80 \\
\end{tabular} & $\begin{array}{c}0.02 * \\
0.19 \\
0.03 *\end{array}$ & 6 \\
\hline $\begin{array}{l}\text { DDS- Interpersonal Distress } \\
\text { All Participants }(n=14) \\
\text { In-Person }(n=7) \\
\text { Online }(n=7)\end{array}$ & $\begin{array}{l}1.66 \\
2.00 \\
1.33 \\
\end{array}$ & $\begin{array}{l}1.38 \\
1.33 \\
1.43 \\
\end{array}$ & $\begin{array}{r}1.03 \\
1.92 \\
-0.25 \\
\end{array}$ & $\begin{array}{l}0.32 \\
0.10 \\
0.81 \\
\end{array}$ & 6 \\
\hline $\begin{array}{l}\text { GAD-7 } \\
\text { All Participants }(n=14) \\
\text { In-Person }(n=7) \\
\text { Online }(n=7) \\
\end{array}$ & $\begin{array}{l}6.36 \\
7.14 \\
5.57 \\
\end{array}$ & $\begin{array}{l}4.21 \\
6.00 \\
2.43 \\
\end{array}$ & \begin{tabular}{|l|}
2.22 \\
0.80 \\
2.42 \\
\end{tabular} & $\begin{array}{c}0.04 * \\
0.45 \\
0.05 \\
\end{array}$ & 21 \\
\hline $\begin{array}{l}\text { PHQ-9 } \\
\text { All Participants }(n=14) \\
\text { In-Person }(n=7) \\
\text { Online }(n=7)\end{array}$ & $\begin{array}{l}6.64 \\
7.29 \\
6.00 \\
\end{array}$ & $\begin{array}{l}6.36 \\
7.71 \\
5.00 \\
\end{array}$ & \begin{tabular}{|c|}
0.26 \\
-0.35 \\
0.52 \\
\end{tabular} & $\begin{array}{l}0.80 \\
0.74 \\
0.62 \\
\end{array}$ & 27 \\
\hline $\begin{array}{l}\text { PSS } \\
\text { All Participants }(n=14) \\
\text { In-Person }(n=7) \\
\text { Online }(n=7)\end{array}$ & $\begin{array}{l}15.14 \\
13.29 \\
17.00\end{array}$ & $\begin{array}{c}14.5 \\
15.43 \\
13.57\end{array}$ & $\begin{array}{c}0.32 \\
-1.37 \\
0.95\end{array}$ & $\begin{array}{l}0.76 \\
0.22 \\
0.38\end{array}$ & 40 \\
\hline $\begin{array}{l}\text { RAND 36-Physical Functioning } \\
\text { All Participants }(\mathrm{n}=14) \\
\text { In-Person }(\mathrm{n}=7) \\
\text { Online }(\mathrm{n}=7)\end{array}$ & $\begin{array}{l}62.14 \\
53.57 \\
70.71\end{array}$ & $\begin{array}{l}66.43 \\
60.00 \\
72.86\end{array}$ & $\begin{array}{l}-0.90 \\
-1.19 \\
-0.26\end{array}$ & $\begin{array}{l}0.39 \\
0.28 \\
0.80\end{array}$ & 100 \\
\hline
\end{tabular}




\begin{tabular}{|c|c|c|c|c|c|}
\hline $\begin{array}{l}\text { RAND 36-Physical Problems } \\
\text { Limitations } \\
\text { All Participants }(n=14) \\
\text { In-Person }(n=7) \\
\text { Online }(n=7)\end{array}$ & $\begin{array}{l}58.93 \\
42.86 \\
75.00\end{array}$ & $\begin{array}{l}61.61 \\
57.14 \\
66.07\end{array}$ & $\begin{array}{c}-0.28 \\
-0.88 \\
0.92\end{array}$ & $\begin{array}{l}0.79 \\
0.41 \\
0.39\end{array}$ & 100 \\
\hline $\begin{array}{l}\text { RAND 36-Emotional Problems } \\
\text { Limitations } \\
\text { All Participants }(n=14) \\
\text { In-Person }(n=7) \\
\text { Online }(n=7) \\
\end{array}$ & $\begin{array}{l}69.05 \\
66.66 \\
71.43 \\
\end{array}$ & $\begin{array}{l}61.91 \\
57.14 \\
66.67 \\
\end{array}$ & \begin{tabular}{|l|}
0.67 \\
0.79 \\
0.26 \\
\end{tabular} & $\begin{array}{l}0.51 \\
0.46 \\
0.80 \\
\end{array}$ & 100 \\
\hline $\begin{array}{l}\text { RAND 36- Energy/Fatigue } \\
\text { All Participants }(n=14) \\
\text { In-Person }(n=7) \\
\text { Online }(n=7)\end{array}$ & $\begin{array}{l}47.14 \\
45.71 \\
48.57\end{array}$ & $\begin{array}{l}52.86 \\
58.57 \\
66.67\end{array}$ & $\begin{array}{c}-0.99 \\
-1.44 \\
0.21\end{array}$ & $\begin{array}{l}0.34 \\
0.20 \\
0.84\end{array}$ & 100 \\
\hline $\begin{array}{l}\text { RAND 36- Emotional Wellness } \\
\text { All Participants }(n=14) \\
\text { In-Person }(n=7) \\
\text { Online }(n=7)\end{array}$ & $\begin{array}{l}74.00 \\
77.71 \\
70.29\end{array}$ & $\begin{array}{l}74.29 \\
74.86 \\
73.71\end{array}$ & $\begin{array}{c}-0.08 \\
0.55 \\
-0.66\end{array}$ & $\begin{array}{l}0.94 \\
0.60 \\
0.53\end{array}$ & 100 \\
\hline $\begin{array}{l}\text { RAND 36- Social Functioning } \\
\text { All Participants }(n=14) \\
\text { In-Person }(n=7) \\
\text { Online }(n=7)\end{array}$ & $\begin{array}{l}61.61 \\
50.00 \\
73.21\end{array}$ & $\begin{array}{l}75.00 \\
69.64 \\
80.36\end{array}$ & $\begin{array}{l}-2.03 \\
-1.66 \\
-1.19\end{array}$ & $\begin{array}{l}0.06 \\
0.15 \\
0.28\end{array}$ & 100 \\
\hline $\begin{array}{l}\text { RAND 36- Pain } \\
\text { All Participants }(n=14) \\
\text { In-Person }(n=7) \\
\text { Online }(n=7)\end{array}$ & $\begin{array}{l}51.07 \\
39.29 \\
62.86\end{array}$ & $\begin{array}{l}70.00 \\
64.29 \\
75.71 \\
\end{array}$ & \begin{tabular}{|l|}
-3.78 \\
-3.43 \\
-1.95 \\
\end{tabular} & $\begin{array}{c}<0.01 * \\
0.01 * \\
0.10\end{array}$ & 100 \\
\hline $\begin{array}{l}\text { RAND 36- General Health } \\
\text { All Participants }(n=14) \\
\text { In-Person }(n=7) \\
\text { Online }(n=7)\end{array}$ & $\begin{array}{c}55 \\
52.86 \\
57.14\end{array}$ & $\begin{array}{l}55.71 \\
55.71 \\
55.71\end{array}$ & $\begin{array}{c}-0.13 \\
-0.30 \\
0.25\end{array}$ & $\begin{array}{l}0.90 \\
0.77 \\
0.81\end{array}$ & 100 \\
\hline $\begin{array}{l}\text { MOCA } \\
\text { All Participants }(\mathrm{n}=14) \\
\text { In-Person }(\mathrm{n}=7) \\
\text { Online }(\mathrm{n}=7)\end{array}$ & $\begin{array}{l}25.29 \\
25.14 \\
25.43\end{array}$ & $\begin{array}{l}26.21 \\
25.71 \\
26.71\end{array}$ & $\begin{array}{l}-1.34 \\
-0.55 \\
-1.33 \\
\end{array}$ & $\begin{array}{l}0.20 \\
0.60 \\
0.23\end{array}$ & 30 \\
\hline $\begin{array}{l}\text { HbA1c } \\
\text { All Participants }\end{array}$ & $8.5 \%$ & $7.7 \%$ & 0.4 & 0.08 & \\
\hline
\end{tabular}




\section{Appendix A: Interview Guide}

Key Questions: Compatibility, Complexity, Observability and Relative Advantage of a Culturally Tailored Cognitive Behavior intervention (CT-CB) for African American patients

1. What was your experience with the cognitive behavioral therapy intervention?

a. Probe: What did you like about it? What didn't you like about it?

2. Have you ever participated in a similar intervention? Please tell us more.

a. Probe: Did you prefer aspects of the other intervention more? Less? How about this intervention?

3. What was confusing about the cognitive behavioral therapy intervention? What didn't make sense to you?

a. Probe: What about it was confusing? How could we have better communicated with you?

4. How has the cognitive behavioral therapy intervention impacted how you manage your diabetes, if at all?

a. Probe: Did you feel like you had more control of your diabetes? Did you feel like you had less control of your diabetes?

5. How did the material presented from the therapy align with your daily activities?

a. Probes: Is it easy to incorporate? What is difficult to incorporate? How would it have been easier to make it as part of your daily life? Have you done something like this before?

Key Questions: Cultural Sensitivity of the Study

1. How could the study improve in making the intervention and experience more comfortable for African American patients?

a. Probe: Did you ever feel uncomfortable? Why?

2. How did study staff make you feel during the intervention?

a. Probe: Words of encouragement? Attitudes? Demographics?

3. How did the staff account for your beliefs and identity when presenting the intervention material?

a. Probe: Words? Actions? Intervention specific components?

Closing Questions/Conclusion

1. If you could advise other African American patients on how to navigate these experiences what would you say?

2. Do you have any final thoughts you would like to share? 
Appendix B: Code System

\begin{tabular}{|c|c|c|c|c|}
\hline Code \# & Code & Sub-code & Definition & Example quotes \\
\hline 1 & $\begin{array}{l}\text { DIABETES } \\
\text { DISEASE } \\
\text { PERSPECTIVE }\end{array}$ & & $\begin{array}{l}\text { How participants view diabetes as } \\
\text { a disease and how they describe it } \\
\text { when discussing the intervention. } \\
\text { Discussions about how diabetes } \\
\text { relates to them are also useful. }\end{array}$ & $\begin{array}{l}\text { "This whole experience } \\
\text { is just a rollercoaster. } \\
\text { Every day you do } \\
\text { everything right, you } \\
\text { take your blood sugar } \\
\text { levels and it's all over } \\
\text { the map" }\end{array}$ \\
\hline 1.1 & & $\begin{array}{l}\text { BALANCE/ } \\
\text { CONTROL }\end{array}$ & $\begin{array}{l}\text { When participants discuss dealing } \\
\text { with aspects of their lives in } \\
\text { relation to diabetes. Reference } \\
\text { could be to diabetes as a disease, } \\
\text { navigating the learning curve of } \\
\text { diabetes, or managing diabetes. }\end{array}$ & $\begin{array}{l}\text { "Sometimes I'm good, } \\
\text { sometimes I'm not so } \\
\text { good. Sometimes the } \\
\text { experiences are good, } \\
\text { sometimes they're not } \\
\text { good." }\end{array}$ \\
\hline 1.2 & & $\begin{array}{l}\text { BEHAVIOR } \\
\text { CHANGE }\end{array}$ & $\begin{array}{l}\text { Mention of action taken to } \\
\text { improve self-management of } \\
\text { diabetes which include a } \\
\text { behavioral change by } \\
\text { participants. }\end{array}$ & $\begin{array}{l}\text { "In my life I found out } \\
\text { that I have a lot more } \\
\text { power to choose what I } \\
\text { do" }\end{array}$ \\
\hline 2 & IDENTITY & & $\begin{array}{l}\text { Any mention of how participants } \\
\text { view themselves or how society } \\
\text { may view them. }\end{array}$ & $\begin{array}{l}\text { "many of us could relate } \\
\text { to it, you know, we've } \\
\text { experience it or we're } \\
\text { living it" }\end{array}$ \\
\hline 2.1 & & SES & $\begin{array}{l}\text { Experiences that participants } \\
\text { describe which are related to the } \\
\text { individual's socioeconomic status } \\
\text { (positive or negative). This may } \\
\text { include costs of treatment and } \\
\text { living expenses. }\end{array}$ & $\begin{array}{l}\text { "It can become, it can } \\
\text { become taxing on the } \\
\text { pocketbook" }\end{array}$ \\
\hline 2.2 & & RACE & $\begin{array}{l}\text { Any mention of race as a social } \\
\text { construct, whether related to } \\
\text { personal identity of the } \\
\text { participant or in relation to } \\
\text { society in general. }\end{array}$ & $\begin{array}{l}\text { "So, this disease impacts } \\
\text { African Americans } \\
\text { somewhat differently } \\
\text { based on culture" }\end{array}$ \\
\hline 3 & $\begin{array}{l}\text { HEALTH } \\
\text { LITERACY/ } \\
\text { KNOWLEDGE }\end{array}$ & & $\begin{array}{l}\text { Mention of information learned } \\
\text { from the CBT intervention. }\end{array}$ & $\begin{array}{l}\text { "You know, the } \\
\text { materials made you think } \\
\text { about things that you } \\
\text { hadn't thought about" }\end{array}$ \\
\hline 4 & COPING & & $\begin{array}{l}\text { Mentions of how participant has } \\
\text { been able to handle the stresses of } \\
\text { diabetes management. }\end{array}$ & $\begin{array}{l}\text { "that particular session } \\
\text { did have an effect on } \\
\text { what I ate during that } \\
\text { stressful situation" }\end{array}$ \\
\hline
\end{tabular}




\begin{tabular}{|c|c|c|c|c|}
\hline 5 & $\begin{array}{l}\text { INFORMATION } \\
\text { SHARING }\end{array}$ & & $\begin{array}{l}\text { Sharing of information with } \\
\text { others concerning diabetes } \\
\text { management and coping } \\
\text { mechanisms. }\end{array}$ & $\begin{array}{l}\text { "I learned a lot of } \\
\text { information from each } \\
\text { and every one of them" }\end{array}$ \\
\hline 5.1 & & IN-GROUP & $\begin{array}{l}\text { Sharing of information in a given } \\
\text { treatment group. }\end{array}$ & $\begin{array}{l}\text { "And we learned some } \\
\text { things from each other } \\
\text { [Group members } \\
\text { verbally agreeing]" }\end{array}$ \\
\hline 5.2 & & PUBLIC & $\begin{array}{l}\text { Discussions of disseminating } \\
\text { information to the public. }\end{array}$ & $\begin{array}{l}\text { "They gotta get it out. In, } \\
\text { you know, be it in spurts } \\
\text { or increments" }\end{array}$ \\
\hline 6 & SELF-EFFICACY & & $\begin{array}{l}\text { Reflections on how participants } \\
\text { have acted to improve their health } \\
\text { when managing their diabetes as } \\
\text { a result of the information learned } \\
\text { from the CBT/MI intervention. }\end{array}$ & $\begin{array}{l}\text { "So, I specifically went } \\
\text { to the store and started } \\
\text { buying vegetables } \\
\text { instead of buying other } \\
\text { things" }\end{array}$ \\
\hline 7 & ACCEPTABILITY & & $\begin{array}{l}\text { Mentions of how well received } \\
\text { the information was by the group } \\
\text { and how they believe it would be } \\
\text { received by other African } \\
\text { American/ Black people. }\end{array}$ & $\begin{array}{l}\text { "I think the materials } \\
\text { were really helpful." }\end{array}$ \\
\hline 7.1 & & APPLICATION & $\begin{array}{l}\text { Mention of acceptability of } \\
\text { material that leads to application } \\
\text { of learned material. }\end{array}$ & $\begin{array}{l}\text { "Umm, problem solving, } \\
\text { you know, um, and just } \\
\text { kind of trying to give } \\
\text { you options and things to } \\
\text { think about, uh, day-to- } \\
\text { day" }\end{array}$ \\
\hline 8 & AGREEMENT & & $\begin{array}{l}\text { When participants express that } \\
\text { they have had the same, or } \\
\text { similar, experiences. Verbal and } \\
\text { non-verbal cues in transcript } \\
\text { should be coded. }\end{array}$ & $\begin{array}{l}\text { "I think because I feel } \\
\text { like it's more people that } \\
\text { are around that are going } \\
\text { through some of the } \\
\text { same things." }\end{array}$ \\
\hline 8.1 & & $\begin{array}{l}\text { CULTURAL } \\
\text { AGREEMENT }\end{array}$ & $\begin{array}{l}\text { Having the same cultural } \\
\text { background or similarity in } \\
\text { cultural practices. }\end{array}$ & No Data Coded. \\
\hline 8.2 & & $\begin{array}{l}\text { TREATMENT } \\
\text { AGREEMENT }\end{array}$ & $\begin{array}{l}\text { When participants express similar } \\
\text { experiences in relation to } \\
\text { treatment (good or bad) }\end{array}$ & $\begin{array}{l}\text { "They've been eye } \\
\text { opening. They've been, } \\
\text { they've been very direct } \\
\text { [Other participant: Mhm } \\
\text { hmm] and it's kind of } \\
\text { made me think out of the } \\
\text { box" }\end{array}$ \\
\hline 9 & $\begin{array}{l}\text { SOCIAL SUPPORT } \\
\text { NETWORK }\end{array}$ & & $\begin{array}{l}\text { Any mention of being encouraged } \\
\text { or finding refuge from others. }\end{array}$ & $\begin{array}{l}\text { "We really had a great } \\
\text { group" }\end{array}$ \\
\hline
\end{tabular}




\begin{tabular}{|c|c|c|c|c|}
\hline 9.1 & & $\begin{array}{l}\text { IN-GROUP } \\
\text { SUPPORT }\end{array}$ & $\begin{array}{l}\text { Encouragement or refuge from } \\
\text { the intervention group. }\end{array}$ & $\begin{array}{l}\text { "Well the intervention } \\
\text { made me feel like, well } \\
\text { I'm not the only one" }\end{array}$ \\
\hline 9.2 & & $\begin{array}{l}\text { AT-HOME/ } \\
\text { SOCIETAL } \\
\text { SUPPORT }\end{array}$ & $\begin{array}{l}\text { Encouragement or refuge from } \\
\text { people outside of intervention } \\
\text { group. }\end{array}$ & No Data Coded. \\
\hline 10 & MENTAL HEALTH & & $\begin{array}{l}\text { Any indication of psychological } \\
\text { status from study participants. }\end{array}$ & $\begin{array}{l}\text { "I feel a reduction in my } \\
\text { life, and does it ever get } \\
\text { any better?" }\end{array}$ \\
\hline 10.1 & & $\begin{array}{l}\text { POSITIVE } \\
\text { MENTAL } \\
\text { HEALTH }\end{array}$ & $\begin{array}{l}\text { Any indication of positive } \\
\text { experiences related to the } \\
\text { patient's state of mind and } \\
\text { diabetes management. }\end{array}$ & $\begin{array}{l}\text { "help you evolve, you } \\
\text { know, into a better } \\
\text { person. So, it's been, it's } \\
\text { been real good." } \\
\end{array}$ \\
\hline 10.2 & & $\begin{array}{l}\text { NEGATIVE } \\
\text { MENTAL } \\
\text { HEALTH }\end{array}$ & $\begin{array}{l}\text { Any mention of desperation or } \\
\text { loss of hope from participants. }\end{array}$ & $\begin{array}{l}\text { "I would say depressed } \\
\text { sometimes." }\end{array}$ \\
\hline 11 & STRESS & & $\begin{array}{l}\text { Any mention of psychological or } \\
\text { emotional distress from } \\
\text { participants. }\end{array}$ & $\begin{array}{l}\text { "And something that } \\
\text { really just "stress me out } \\
\text {, and automatically I } \\
\text { would've went to eating } \\
\text { something that, you } \\
\text { know, people say } \\
\text { comfort food or } \\
\text { whatever. [ }\end{array}$ \\
\hline 12 & $\begin{array}{l}\text { INTERVENTION } \\
\text { RECEPTIVITY \& } \\
\text { MINDSET }\end{array}$ & & $\begin{array}{l}\text { Discussions about how well } \\
\text { received study materials and } \\
\text { intervention was by participants } \\
\text { and what their state of mind was. }\end{array}$ & $\begin{array}{l}\text { "It's making me feel like } \\
\text { I can grow, you know, } \\
\text { dealing with them and } \\
\text { they've changed a lot of } \\
\text { things, you know, as far } \\
\text { as medication and all." }\end{array}$ \\
\hline 12.1 & & $\begin{array}{l}\text { POSITIVE } \\
\text { RECEPTION }\end{array}$ & $\begin{array}{l}\text { Discussions of when intervention } \\
\text { materials were well received. }\end{array}$ & $\begin{array}{l}\text { "One thing it helped me } \\
\text { with is periodically I } \\
\text { know I was gonna feel } \\
\text { accountable when we } \\
\text { had the meeting, so it } \\
\text { kind of inspired me to do } \\
\text { better" }\end{array}$ \\
\hline 12.2 & & \begin{tabular}{|l} 
NEGATIVE \\
RECEPTION
\end{tabular} & $\begin{array}{l}\text { Discussions of when intervention } \\
\text { materials were not well received. }\end{array}$ & No Data Coded. \\
\hline 13 & $\begin{array}{l}\text { ENVIRONMENTAL } \\
\& \text { ECOLOGICAL } \\
\text { FACTORS }\end{array}$ & & $\begin{array}{l}\text { Discussions about how } \\
\text { participant environment affected } \\
\text { the use of materials from the } \\
\text { study intervention by participants. }\end{array}$ & $\begin{array}{l}\text { "Go to a cooking class } \\
\text { and learn how to make } \\
\text { the foods that you like in } \\
\text { a different way" }\end{array}$ \\
\hline
\end{tabular}




\begin{tabular}{|l|l|l|l|l|}
\hline 14 & CBT/MI IMPACT & $\begin{array}{l}\text { Any mention of how CBT/MI has } \\
\text { contributed to treatment of } \\
\text { disease or how the information } \\
\text { has been received by participants. }\end{array}$ & "It was helpful." \\
\hline 14.1 & & $\begin{array}{l}\text { POSITIVE } \\
\text { CBT/MI }\end{array}$ & $\begin{array}{l}\text { How CBT/MI has contributed to } \\
\text { participants positively. }\end{array}$ & "low CBT/MI has contributed to \\
\hline 14.2 & & $\begin{array}{l}\text { NEGATIVE } \\
\text { CBT/MI }\end{array}$ & $\begin{array}{l}\text { Now Data Coded. } \\
\text { participants negatively. }\end{array}$ \\
\hline 14.3 & & $\begin{array}{l}\text { CBT/MI } \\
\text { IMPROVEMENT }\end{array}$ & How CBT/MI can be improved. & $\begin{array}{l}\text { "I think that we could've } \\
\text { gotten suggestions. } \\
\text { Recipes or things to } \\
\text { avoid." }\end{array}$ \\
\hline
\end{tabular}




\section{Supplementary Files}

This is a list of supplementary files associated with this preprint. Click to download.

- ReportingChecklist.pdf 